\section{International Journal of Learning and Teaching}

Volume 09, Issue 4, (2017) 411-417

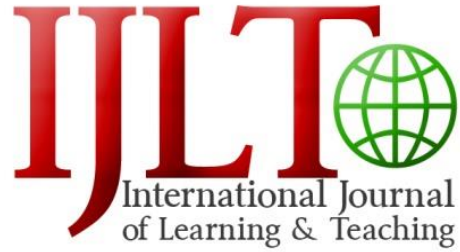

www.ij-lt.eu

\title{
The use of speaking techniques by Native and Non-Native English instructors: A case in Turkey
}

Enisa Mede ", Bahcesehir University, Besiktas, Istanbul, 34353, Turkey.

Gulcin Cosgun, Ozyegin University, Cekmekoy, Istanbul, 34794, Turkey.

Derin Atay, Bahcesehir University, Besiktas, Istanbul, 34353, Turkey.

\section{Suggested Citation:}

Mede, E., Cosgun, G. \& Atay, D. (2017). The use of speaking techniques by Native and Non-Native English instructors: A case in Turkey. International Journal of Learning and Teaching. 9(4), 411-417.

Received May 25, 2017; revised August 5, 2017; accepted October 10, 2017

Selection and peer review under responsibility of Prof. Dr. Hafize Keser, Ankara University, Ankara, Turkey.

${ }^{\circ} 2016$ Science Park Research, Organization \& Counseling. All rights reserved

\section{Abstract}

Although the primary goal of English language instruction is to assist students in acquiring communicative competence in I, developing this ability might be very challenging for teachers since not all language learners of English are willing to communicate in the target language. In order to develop their learners' communication skills and increase their students' willingness to speak, teachers utilize different techniques. The aim of this qualitative study is to find out and compare the speaking techniques that are used by native (NESTs) and non-native (NNESTs) instructors of English Preparatory Programs at universities around Turkey. Data gathered from the open-ended questionnaire revealed both similarities and differences among NESTs and NNESTs about implementing various techniques in EFL speaking classes. The findings of the study suggested some pedagogical implications both for instructors and students in relation to the improvement of the students' oral performance in language preparatory programs.

Keywords: Speaking techniques, native instructors, non-native instructors, NESTs, NNESTs.

\footnotetext{
* ADDRESS FOR CORRESPONDENCE: Enisa Mede, Bahcesehir University, Besiktas, Istanbul, 34353, Turkey 
Mede, E., Cosgun, G. \& Atay, D. (2017). The use of speaking techniques by Native and Non-Native English instructors: A case in Turkey. International Journal of Learning and Teaching. 9(4), 411-417.

\section{Introduction}

In today's globalized world, developing oral proficiency in English has become the primary goal to maintain international communication as well as to achieve career- and academic-related goals. English language instruction aims to assist students in acquiring communicative competence that achieves fluency, accuracy, and appropriateness in language use so that they can speak in different contexts and in a range of topics. However, a number of studies have shown that students, especially in the EFL settings, are not willing to communicate in the target language (Savasci, 2013; Liu, 2005; Zou, 2004) because of various reasons. In a study with Turkish EFL students, Tokoz-Goktepe (2014) found out that the students mostly experienced communication problems in speaking English due to their insufficient language knowledgeand resorted to Turkish. Other studies reported that anxiety and student performance in L2 communication are positively correlated (Liu \& Jackson, 2008; Sheen, 2008). Marzec-Stawiarska (2015) found that students were worried about their fluency, vocabulary, pronunciation and content of their oral performances; and were afraid of making errors and being called on to speak spontaneously.

Apart from student-related factors, teachers play a significant role factor in encouraging students to speak. According to Harmer (1991), the decisions that teachers make about how to react to students' performance and the ways that they use to give feedback affect student communication. If students are not provided with constructive feedback on their output, they get very demotivated and afraid to speak (Baker \& Westrup, 2003). Tsui (1996) reported that the ways teachers use while interacting with students affect students' willingness to speak and identified intolerance of silence, uneven allocation of turns, incomprehensible inputand short wait time as the factors causing learner reticence in classrooms. Tokoz-Goktepe (2014) also found that $49 \%$ of the students participating in the study claimed that they do not communicate in English because their teachers did not motivate them to speak in English. In a recent study, Lee and $\mathrm{Ng}$ (2010) found out that teacher interaction strategy, the pedagogical goals of the lesson and the task/activities used were the major determinants of student reticence in language classrooms.

The aim of the present study is to further explore the crucial role teachers play in developing learners' communication skills by focusing on different speaking strategies that native Englishspeaking teachers (NESTs) and non-native English speaking teachers (NNESTs) utilize in their classrooms.

\section{Literature Review}

English, the lingua franca of our time, is taught by both native and non-native speaker teachers, the number of whom has increased dramatically in the last decades. The fact that English is the language of the world and that English instruction is not in the hegemony of the "native speakers" has led to a NEST versus NNEST debate and many studies have addressed the attitudes and preferences in regards to NESTs and NNESTs (Cheung \& Braine, 2007; Lasagabaster \& Sierra, 2002).

Medgyes (2001) exploring the differences between NESTs and NNESTs in their teaching behaviors found out that NESTs use English more confidently and in a better way than NNESTs. NESTs adopt a more flexible approach and attend to the perceived needs while NNESTs adopt a more guided approach and attend to real needs. Regarding their attitudes to teaching the language, NESTs are found to teach items in context, prefer free activities, favor group work, tolerate errors and use no/less L1. NNESTs, on the contrary, teach items in isolation, prefer controlled and fronted activities, set more tests/assignments and use more L1. NESTs' and NNESTs' focus of concern in the lesson also differs. NESTs focus on fluency, meaning, the language in use, oral skills and colloquial registers while NNESTs focus on accuracy, form, grammar rules, printed word and formal registers. In his doctoral dissertation, Moussu (2006) found that while NESTs reported a high level of self-confidence in teaching writing/composition, speaking/oral communication and culture, NNESTs had higher selfconfidence in teaching grammar compared to their native counterparts. Yi and Jian (2009) also reported striking differences between NESTs and NNESTs related with classroom interaction in the teaching environment. They found out that NNESTs provide more language input and feedback for their students, but more uptake is observed in NESTs' classrooms. Moreover, a higher frequency of teacher questions, student responses and teacher feedback was observed in the NNESTs' lessons while more genuine and natural communication occurred between NESTs and their students. While NNESTs preferred convergent questions more and NESTs' preferred to ask procedural questions more. NESTs and NNESTs differed in feedback types, NESTs giving evaluation feedback, followed by a 
Mede, E., Cosgun, G. \& Atay, D. (2017). The use of speaking techniques by Native and Non-Native English instructors: A case in Turkey. International Journal of Learning and Teaching. 9(4), 411-417.

summary and then acknowledgement feedback, while NNESTs using repetition feedback, followed by acknowledgement and then clarification feedback.

In a recent study, Inan (2012) compared the classroom interaction patterns such as turn-taking, teacher feedback, teacher echo and different kinds of scaffolding strategies adopted by NESTs and NNESTs in EFL settings. The findings of her study suggest that the common interactional pattern in the classrooms is IRE (Initiate, Response and Evaluation), and alternative questions technique is the most common scaffolding technique used by both groups of teachers.

Although the majority of the studies seem to agree that NESTs and NNESTs might have differences, "one group can complement the other in their strengths and weaknesses" (Merino, 1997, p. 69). Medgyes (1992) argued that an ideal EFL environment maintains a balance between NESTs and non-NESTs, where they complement each other in their strengths and weaknesses. Similarly, Samimy and Brutt-Griffler (1999) suggest that 'ELT professionals should sharpen their expertise to become catalysts to the better understanding of the issues related to both non-native and native ELT professionals' (p. 69). Thus, the present study aims to explore the distinctive characteristics NESTs and non-NESTs bring to their teaching environment to cultivate learners' communication skills. In today's globalized world, developing oral proficiency in English has become the primary goal to maintain international communication as well as to achieve career- and academic-related goals. English language instruction aims to assist students in acquiring communicative competence that achieves fluency, accuracy, and appropriateness in language use so that they can speak in different contexts and in a range of topics. However, a number of studies have shown that students, especially in the EFL settings, are not willing to communicate in the target language.

\section{Methodology}

\subsection{Participants and setting}

134 instructors ( 83 females, 31 males) working at the English language preparatory programs of different state and private universities in Istanbul participated in this study. Their age range was between 25 and 45 years, and had 5-15 years of teaching experience. 78 of the participants were Turkish (NNESTs) and 56 were native speakers (NESTs), i.e., British, American, Canadian and Australian. All had a BA or an MA degree in the field of English Language Teaching.

The English preparatory programs aim to equip students with a high command of written and oral English, and to prepare them for their further studies. All students are required to take a proficiency exam at the beginning of the academic year. Those who have a passing score determined by the university start the undergraduate program, whereas the ones who are not successful are placed in different proficiency level classes in alignment with the CEFR.

\subsection{Data collection and instruments}

For the purposes of this study, all the participants were asked to complete an online open-ended questionnaire comprising eight questions regarding teaching speaking in EFL classrooms. Before the questionnaire was administered, it was subject to two rounds of piloting. The first piloting included 76 NESTs and NNESTs whereas the second round comprised 58 participating instructors. In both rounds of piloting, completion rates and distribution of responses to questions were assessed to help refine the questions. Each pilot included interviews to test the face validity of the questionnaire as well as to help refine the wording and layout of the questionnaire. Based on the piloting results, the final version of the questionnaire was developed.

\subsection{Data analysis}

In this qualitative study, data gathered from online questionnaires were analyzed through inductive content analysis (Miles \& Huberman, 1994). The process began with the open coding of the data by the two researchers who were experts in the field of English Language Teaching (ELT). Specifically, the two researchers began coding the documents by identifying the text segments and inducing patterns related to the student motivation in speaking classes, speaking strategies, tasks and 
Mede, E., Cosgun, G. \& Atay, D. (2017). The use of speaking techniques by Native and Non-Native English instructors: A case in Turkey. International Journal of Learning and Teaching. 9(4), 411-417.

materials, type of feedback and evaluation strategies that have been self-reported by NESTs and NNESTs. To identify the degree of interrater reliability, two experts in the field of qualitative data analysis identified the categories and interpreted the data. It emerged that the raters achieved .82 agreement on the induced categories apart from the different verbalizations of similar concepts.

\subsection{Results}

The data gathered from the online questionnaire was reported parallel to the research questions.

\subsubsection{Lack of student motivation}

When the NESTs and non-NESTs were asked about their perceptions on student motivation in English speaking classes, they all agreed that the students are mostly demotivated, as indicated in the following quotes:

"Students in my class are not motivated at all in English speaking classes. They are not confident and generally stay quiet." (NESTs, 2nd Jan., 2017)

"The preparatory students are reluctant to speak. They do not want to participate when it comes to speaking in English. Rather, they express themselves in Turkish." (NNESTs, 2nd Jan., 2017)

The factors causing this reticence are shown in these comments:

"The students are afraid of making mistakes. They think that their friends will make fun of them." (NESTs, 2nd Jan., 2017)

"The students don't like speaking as they are unfamiliar with many words. They are not involved in much speaking practice either" (NNESTs, 2nd Jan., 2017)

\subsubsection{Strategies, materials and tasks used to promote the English speaking ability of the students}

Analysis of the third question revealed that while the NESTs preferred involving students in collaborative tasks such as pair and groups work as well as ask them to take part in discussions and debates, the NNESTs focused more on teacher-student interaction in English speaking classes. To put it differently, the NESTs tried to engage students in collaborative tasks, assigning them different roles and NNESTs preferred individual questions and prompts during communicative activities, focusing more on personalization. The following excerpts support the different speaking strategies used by the instructors:

"I try to promote speaking in my classes engaging students in pair or group work. I assign them different roles during speaking activities." (NESTs, 2nd Jan., 2017)

"I prefer to ask questions and ask each student to answer it individually. I also give them some clues while speaking. (NNESTs, 2nd Jan., 2017)

Furthermore, for the speaking tasks and activities, the two groups highlighted the importance of discussions and debates, as indicated in the following comments:

"I ask students to perform role plays. For example, if our topic is shopping, one of the students is the costumer and the other one the cashier." (NESTs, 2nd Jan., 2017)

"I think debates are important for the development of speaking. Students actively use the language and express their ideas." (NNESTs, 2nd Jan., 2017)

On the other hand, there were some differences in terms of the use of speaking tasks/activities. While NESTs stated that they used information gap activities as well as real-life tasks to promote speaking, NNESTs asked short questions to the students and set a time limit for them (e.g. one minute) to talk about the topic as reported in these excerpts:

"I ask my students to talk about real tasks. I mostly use information gap activities. This will help them improve their speaking more effectively." (NESTs, 2nd Jan., 2017) 
Mede, E., Cosgun, G. \& Atay, D. (2017). The use of speaking techniques by Native and Non-Native English instructors: A case in Turkey. International Journal of Learning and Teaching. 9(4), 411-417.

"I generally ask short questions and give the students a certain amount of time to answer" (NNESTs, 2nd Jan., 2017)

Moreover, both groups agreed that they used videos and visuals to encourage students to speak, as displayed in these excerpts:

"Students love watching videos. It is interesting for them and makes them speak about what they watch." (NESTs, 2nd Jan., 2017)

"I use pictures and photos in my speaking classes a lot. Students love talking about them and they use their creativity." (NNESTs, 2nd Jan., 2017)

\subsubsection{Type of feedback used in students' oral production}

When asked about the type of feedback used in students' oral production, both NESTs and NNESTs highlighted the importance of oral and written feedback as displayed below:

"I listen to the students and then, give them oral feedback. I also provide them with some written feedback after the speaking lesson." (NESTs, 2nd Jan., 2017)

"I mostly use oral and written feedback focusing on the strengths and weaknesses of the students' oral production." (NNESTs, 2nd Jan., 2017)

\subsubsection{Evaluation strategies to assess the students' speaking performance}

Both groups stated that students wanted to know how their speaking performance in class was assessed. Two of the participants said:

"While my students do short presentations or debates, I use a checklist to assess their performance. We also have a speaking exam at each level and use a rubric for assessment." (NESTs, 2nd Jan., 2017)

"In class, we use a checklist while students are making a presentation or discussing a point. In the speaking exam, we use a speaking rubric." (NNESTs, 2nd Jan., 2017)

\section{Conclusion and Suggestions for Further Research}

The present study offers a comparison of strategies used by NESTs and NNESTs during oral communication in Turkish EFL classes. Results reveal that all teachers agreed that Turkish students are the most reticent in EFL classrooms by stating that the factors that affect the motivation are related to the students' anxiety level, their fear of making mistakes and being laughed at by their peers, along with the lack of practice and vocabulary knowledge. These findings are very similar to the findings of Dwyer and Heller-Murphy (1996) who reported that Japanese students were not willing to communicate due to fear of public failure, fear of making mistakes, lack of confidence, and low English proficiency. These findings suggest significant implications for both NESTs and NNESTs. Both groups need to be aware of the key role they play in encouraging their students to speak English. Their main purpose should be boosting students' confidence by developing students' communicative competence as well as lowering their anxiety.

Results of the study also indicate that NESTs and NNESTs utilized different strategies to cultivate students' speaking skills. Although both groups highlighted the importance of discussions and debates to develop students' speaking skills, the NESTs reported that they mostly prefer collaborative 
Mede, E., Cosgun, G. \& Atay, D. (2017). The use of speaking techniques by Native and Non-Native English instructors: A case in Turkey. International Journal of Learning and Teaching. 9(4), 411-417.

speaking skills through different tasks used by both groups. They will also benefit from the different types of feedback given by their NESTs and NNESTs. Another pedagogical suggestion that has emerged is that institutions should promote various forms of cooperation between NESTs and NNESTs. Through some training sessions, both NESTs and NNESTs can be assisted to extend their notions of a good English teacher by emphasizing how the differences between these groups can benefit teaching language. NESTs and NNESTs should also be encouraged to incorporate strategies of the other group into their teaching. In order to achieve this, idea sharing sessions in which NESTs and NNESTs exchange their thoughts and effective teaching practices should be held. In addition to these sessions, both NESTs and NNESTs can conduct peer observations and learn about each other's strengths as well as reflect on their own teaching.

\section{References}

Baker, J., \& Westrup, H. (2003). Essential speaking skills: A handbook for English language teachers. London: Continuum.

Cheung, Y. L., \& Braine, G. (2007). The attitudes of university students towards non-native speakers English teachers in Hong Kong. RELC Journal, 38(3), 257-277.

Dwyer, E., \& Heller-Murphy, A. (1996). Japanese learners in speaking classes. Edinburgh Working Papers in Applied Linguistics, 7, 46-55.

Harmer, J. (1991). The practice of English language teaching ( $3^{\text {rd }}$ edition). Longman: London.

Inan, B. (2012). A comparison of classroom interaction patterns of native and nonnative EFL teachers. Social and Behavioral Sciences, 46(2012), 2419-2423.

Lasagabaster, D., \& Sierra, J. M. (2002). University students' perceptions of native and non-native speaker teachers of English. Language Awareness,11(2), 132-142.

Lee, W., \& Ng, S. (2010). Reducing student reticence through teacher interaction strategy. ELT Journal, 64(3), 302-313.

Liu, M. (2005). Reticence in oral English language classrooms: A case study in China. TESL Reporter, 38(1), 1-16.

Liu, M., \& Jackson, J. (2008). An exploration of Chinese EFL learners' unwillingness to communicate and foreign language anxiety. Modern Language Journal, 92, 71-86.

Marzec-Stawiarska, M. (2015). Investigating Foreign Language Speaking Anxiety Among Advanced Learners of English. In M. Pawlak. \& E. Waniek-Klimczak (Eds), Issues in teaching, learning and testing speaking in a second language (pp.103-120). Berlin: Springer.

Medgyes, P. (1992). Native or non-native: who's worth more? ELT journal, 46(4), 340-349.

Medgyes, P. (2001). When the teacher is a non-native speaker. In M. Celce-Murcia, Teaching English as a second or foreign language. (pp. 429-442). Boston: Heinle and Heinle.

Merino, I. G. (2007). Native English-speaking teachers versus non-native English-speaking teachers. Revista alicantina de estudios ingleses, 10, 67-79.

Moussu, L. M. (2006). Native and nonnative English-speaking English as a second language teachers: student attitudes, teacher self-perceptions, and intensive English administrator beliefs and practices. Ph.D. Dissertation, Purdue University, United States.

Samimy, K., \& Brutt-Griffler, J. (1999). "To be a native or non-native speaker: perceptions of non-native students in a Graduate TESOL Program". In G. Braine (Ed.), Non-native educators in English language teaching (pp.127-144). London: Lawrence Erlbaum.

Savasci, M. (2013). Why are some students reluctant to use L2 in EFL speaking classes? An action research at tertiary level. Procedia - Social and Behavioral Sciences, 116(2014), 2682-2686.

Sheen, Y. (2008). Recasts, language anxiety, modified output, and L2 learning. Language Learning, 58(4), 835874.

Tokoz-Goktepe, F. (2014). Speaking problems of 9th grade high school Turkish learners of L2 English and possible reasons for those problems: Exploring the teachers and students' perspectives. Procedia - Social and Behavioral Sciences, 116(2014), 1875-1879. 
Mede, E., Cosgun, G. \& Atay, D. (2017). The use of speaking techniques by Native and Non-Native English instructors: A case in Turkey. International Journal of Learning and Teaching. 9(4), 411-417.

Tsui, A. B. M., (1996). Reticence and anxiety in second language learning. In K. M. Bailey \& D. Nunan (Eds.), Voices from the language classroom (pp. 145-167). Cambridge: Cambridge University Press.

Yi, Z. \& Jian, W. (2009). A comparative study of NEST and NNEST classroom interaction in Chinese context. CELEA Journal, 32(2), 92-102.

Zhang, Y., \& Elder, C. (2001). Judgments of oral proficiency by nonnative and native English speaking teacher raters: Competing or complementary constructs? Language Testing, 28(1), 31-50.

Zou, M. (2004). EFL learners' perceptions of in-class relationships and their voluntary responses. In Y. Gao (Ed.), The Social Psychology of English Learning by Chinese College Students (pp. 149-167). Beijing: Foreign Language Teaching and Research Press. 